Article

\title{
Analysis of a Three-Level Bidirectional ZVS Resonant Converter
}

\author{
Bor-Ren Lin * and Wei-Po Liu \\ Department of Electrical Engineering, NYUST, 123, Section 3, University Road, Yunlin 640, Taiwan; \\ weber519liu@gmail.com \\ * Correspondence: linbr@yuntech.edu.tw; Tel.: +886-912-312-281
}

Received: 9 November 2020; Accepted: 18 December 2020; Published: 21 December 2020

\begin{abstract}
A bidirectional three-level soft switching circuit topology is proposed and implemented for medium voltage applications such as $750 \mathrm{~V}$ dc light rail transit, high power converters, or dc microgrid systems. The studied converter is constructed with a three-level diode-clamp circuit topology with the advantage of low voltage rating on the high-voltage side and a full-bridge circuit topology with the advantage of a low current rating on the low-voltage side. Under the forward power flow operation, the three-level converter is operated to regulate load voltage. Under the reverse power flow operation, the full-bridge circuit is operated to control high-side voltage. The proposed $L L C$ resonant circuit is adopted to achieve bidirectional power operation and zero-voltage switching (ZVS). The achievability of the studied bidirectional ZVS converter is established from the experiments.
\end{abstract}

Keywords: PWM converters; resonant converter; frequency control; analog circuit

\section{Introduction}

Renewable power to reduce the effect of global warming has been developed by using high efficiency power electronic based converters in local dc nanogrid or microgrid distribution [1-6] between renewable energy power and local dc or ac loads. In order to maintain the voltage stability on dc distribution system, energy storage power units are usually demanded between battery banks and dc bus system to save (or restore) excess (or insufficient) energy on the dc bus. Therefore, the bidirectional pulse-width modulation (PWM) converters have been proposed for the battery-based systems [7-14] such as electric vehicles, hybrid electric vehicles, and dc microgrids. In dc microgrids, the unipolar voltage $(380 \mathrm{~V})$ or bipolar voltage $( \pm 380 \mathrm{~V}$ or $760 \mathrm{~V})$ distribution can be adopted on the dc bus voltage. High frequency link medium voltage converters have been used for dc traction power units, three phase industry power supplies and dc microgrids. Three-level dc converters with $600 \mathrm{~V}$ MOSFETs or conventional PWM converters with 1200 V IGBTs or SiCs have been presented in medium voltage input applications. The drawback of $1200 \mathrm{~V}$ IGBT is low switching frequency and the cost of $1200 \mathrm{~V}$ $\mathrm{SiC}$ is expensive. Bidirectional PWM converters with dual active bridge (DAB) structure have been studied to realize forward and reverse power transfer. Three-level bidirectional converters or cascaded converters with the high frequency MOSFETs have been developed for high voltage systems such as $760 \mathrm{~V}$ input. PWM scheme is widely adopted in bidirectional DAB systems to control power flow and realize soft switching turn-on characteristics. However, the control scheme for generating the PWM signals is complicated and the circulating current under low duty cycle is high. Resonant converters have the benefits of high circuit efficiency and low electromagnetic interference. A full-bridge resonant circuit topology was proposed in [15] to achieve bidirectional power transfer. However, the soft switching characteristics cannot be achieved in backward power flow. Bidirectional Full-bridge resonant converters presented in [16-18] have symmetric circuit structure to achieve forward and backward power flow so that power switches can realize zero-voltage switching. However, there is a 
circulating current on the parallel inductor in primary-side which will result in addition conduction loss during forward power flow.

A soft switching three-level resonant converter is developed for high voltage to low voltage conversion. The profits of the developed converter are forward and backward power flow capability and zero-voltage turn-on characteristic. Three-level diode-clamp circuit topology is used on the primary-side and full-bridge circuit topology is adopted on the secondary-side. The LLC circuit tank is employed to control load voltage and achieve zero-voltage switching on active devices. For forward power transfer, the three-level diode-clamp converter is controlled using the pulse-frequency modulation (PFM) to control low-side voltage and active devices of full-bridge converter on the secondary-side are operated as synchronous rectifiers. In order to implement the same resonant circuit structures for bidirectional power flow, an additional inductor is connected on the primary-side during the reverse power flow condition. In reverse power flow operation, the full-bridge converter on the low-voltage side is operated with PFM scheme to control high-side voltage. The proposed converter with bidirectional power flow capability can be applied in local dc nanogrid or microgrid distribution between renewable energy power and local dc or ac loads. The circuit schematic and circuit operation are provided and discussed in Sections 2 and 3. The circuit characteristic and experiments with a $1.44 \mathrm{~kW}$ laboratory circuit are demonstrated and discussed to show the feasibility of the studied bidirectional power converter in Section 4. Finally, a conclusion of the studied converter is given in Section 5.

\section{Circuit Schematic of the Developed Converter}

Figure 1a provides the converter schematic of the studied bidirectional converter. There is a three-level diode-clamp circuit topology on the high-voltage side with the benefit of using low voltage rating switches. Clamped diodes $D_{a}$ and $D_{b}$ and capacitor $C_{f}$ are used to balance input voltages $V_{C H 1}$ $=V_{C H 2}$ and reduce the voltage stress on $S_{1} \sim S_{4}$. Full bridge circuit topology is used on the low-voltage side to achieve full-wave rectification. $S_{a c}$ and $L_{b}$ are series-connection and connect to points $a$ and $b$ in order to achieve $L L C$ circuit operation under backward power flow operation $\left(S_{a c}\right.$ is ON). For forward power operation from $V_{H}$ (high-side voltage) to $V_{L}$ (low-side voltage), $S_{a c}$ is OFF and $L_{b}$ is disconnected on the primary-side. Figure $1 \mathrm{~b}$ gives the circuit structure under forward power operation. $S_{1} \sim S_{4}$ are main power devices to control output voltage $V_{L} . L_{r}, L_{m}$ and $C_{r}$ are $L L C$ resonant circuit and $Q_{1} \sim Q_{4}$ are activated as synchronous switches. For reverse power operation from the $V_{L}$ terminal to the $V_{H}$ terminal, $S_{a c}$ is $\mathrm{ON}$ and Figure 1c provides the circuit diagram of reverse power operation. Switches $Q_{1} \sim Q_{4}$ are major power switches and $L_{r}, L_{b}$ and $C_{r}$ are resonant circuit. $D_{S 1} \sim D_{S 4}$ are operated as a full-wave diode rectifier. Therefore, $L L C$ resonant characteristics for both power flow are achieved and the turn-on switching loss of major power switches is removed.

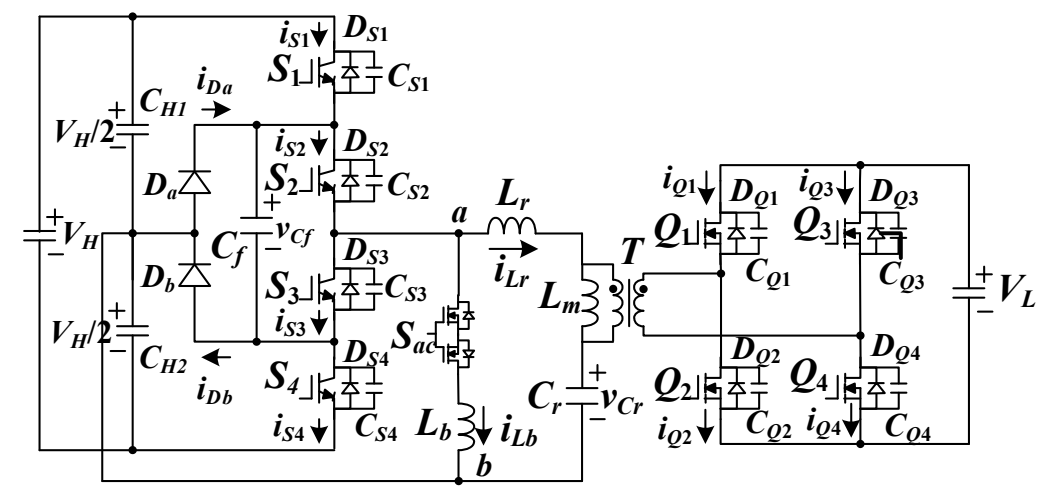

(a)

Figure 1. Cont. 


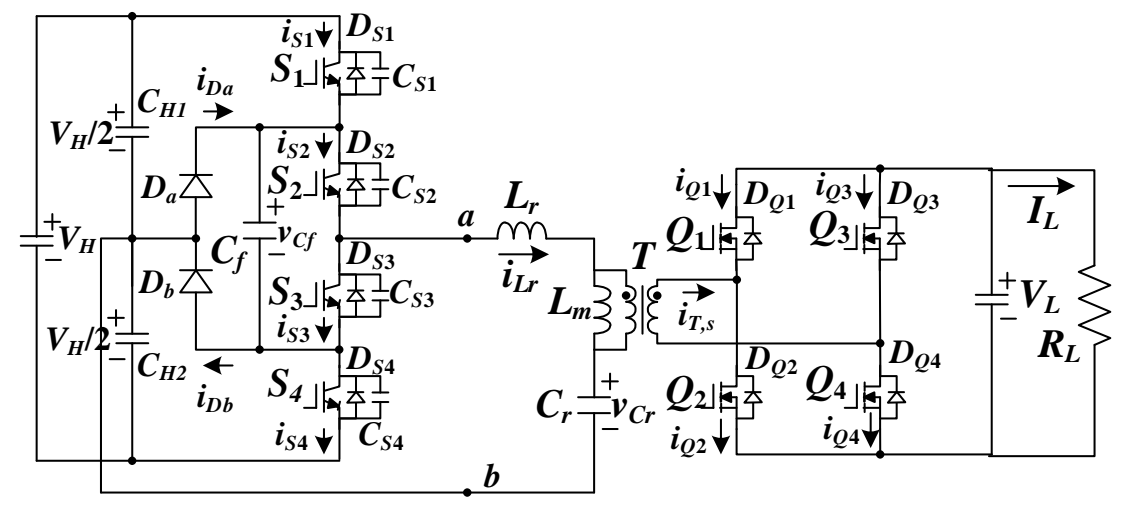

(b)

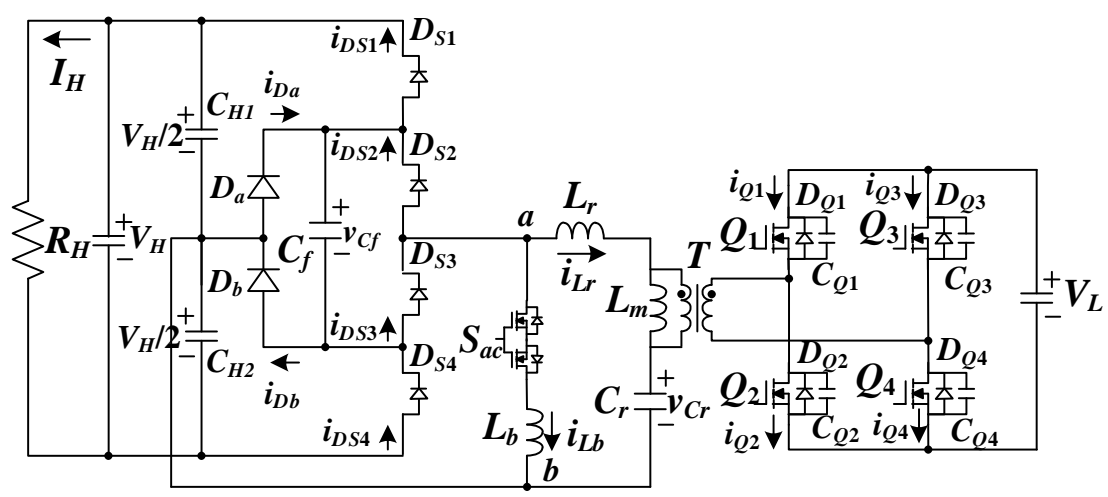

(c)

Figure 1. Proposed converter (a) converter structure (b) forward power flow operation ( $S_{a c}$ off) (c) backward power flow operation $\left(S_{a c}\right.$ on, $S_{1} \sim S_{4}$ off).

\section{Circuit Operation}

For forward power delivery, the electric power energy is transferred from $V_{H}$ side to $V_{L}$ side and $S_{a c}$ is OFF. $S_{1} \sim S_{4}$ are controlled with PFM scheme. Due to PWM signals of $S_{1} \sim S_{4}$, there is a square wave with $-V_{H} / 2$ or $V_{H} / 2$ on the leg voltage $v_{a b}$. However, $Q_{1} \sim Q_{4}$ are operated as the synchronous switches instead of the rectifier diodes in conventional full-bridge rectifier to reduce conduction loss. The equivalent resonant circuit and PWM waveforms for forward power delivery are provided in Figure 2. To realize the ZVS operation of $S_{1} \sim S_{4}$, the input impedance of $L L C$ circuit must be inductive. Figure 3 gives the corresponding equivalent circuits related to six operating steps in a switching period under $f_{r}$ (resonant frequency) $>f_{s w}$ (switching frequency). It is assumed that the $L_{r}$ represents the external series resonant inductance and the leakage inductance of transformer and $C_{r}$ represents the external series resonant capacitance and the parasitic capacitance on transformer winding turns. The output capacitances $C_{S 1}-C_{S 4}$ are assumed to be identical. In the same manner, $C_{Q 1}=\ldots=C_{Q 4}$. Since the current $i_{C f}$ on $C_{f}$ is less than $i_{S 1}$ and $i_{S 2}$ in mode 1 and $i_{S 3}$ and $i_{S 4}$ in mode $4, i_{C f}$ is ignored in PWM waveforms. Therefore, $i_{S 1}$ is equal to $i_{S 2}$ in steps $1-3$ and 6 and $i_{S 3}$ is equal to $i_{S 4}$ in steps 3-6. 


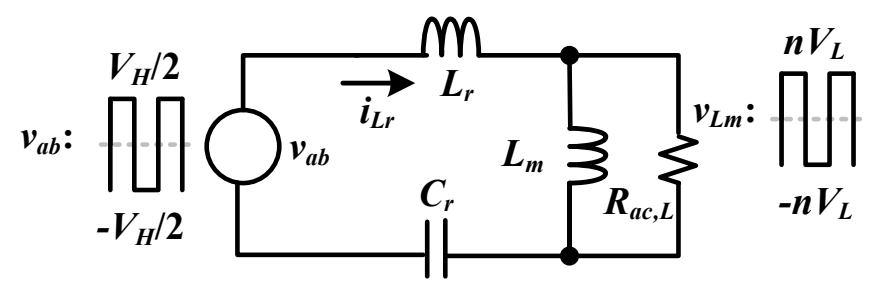

(a)

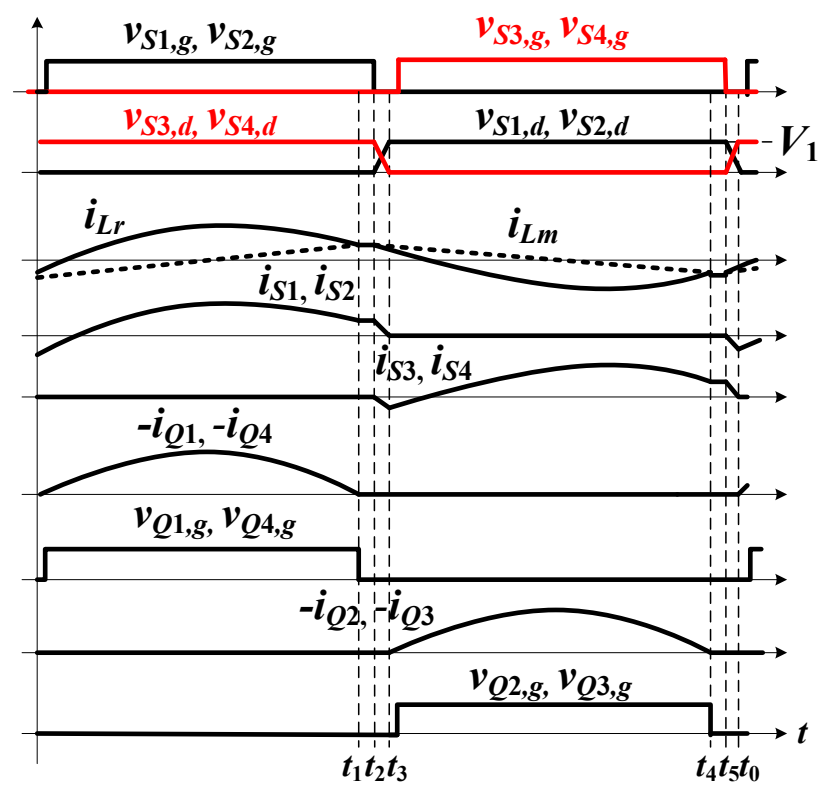

(b)

Figure 2. Forward power operation (a) the equivalent $L L C$ resonant circuit (b) pulse-width modulation (PWM) waveforms.

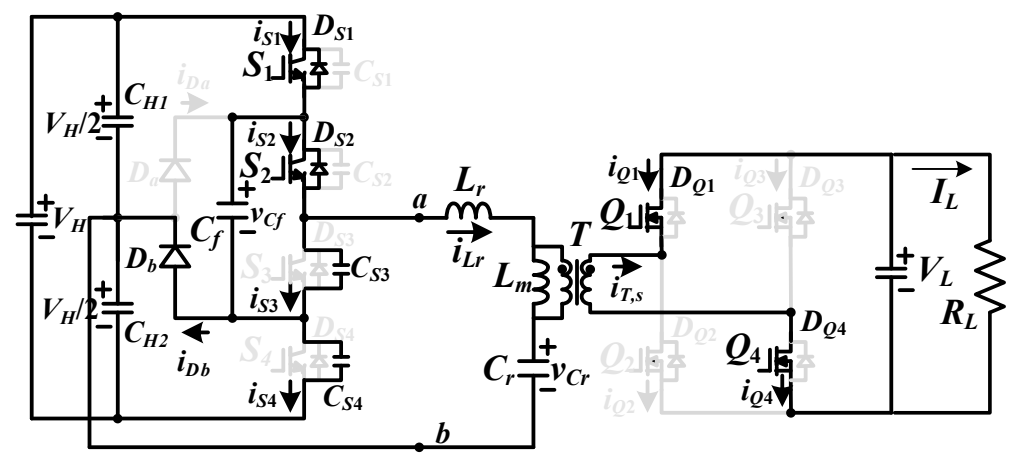

(a)

Figure 3. Cont. 


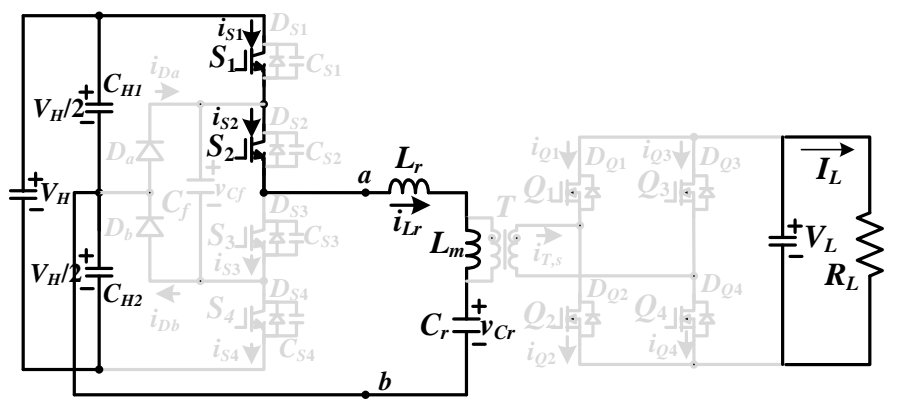

(b)

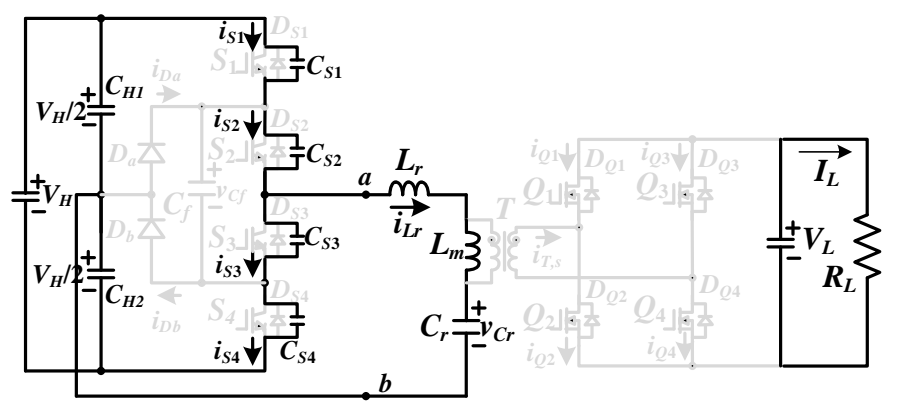

(c)

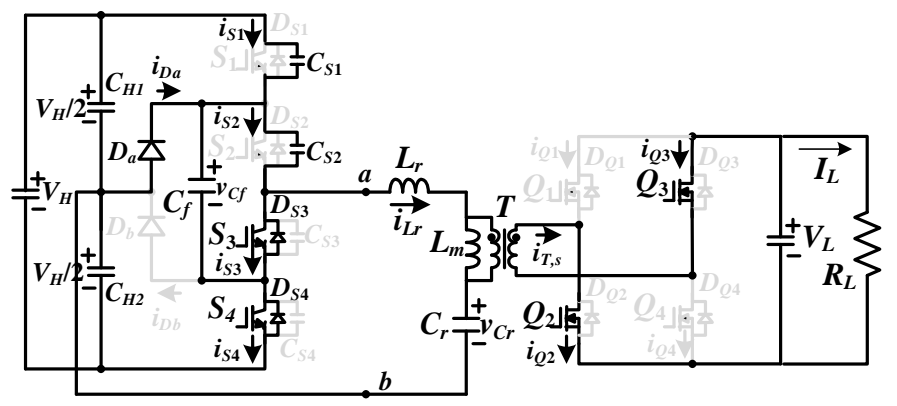

(d)

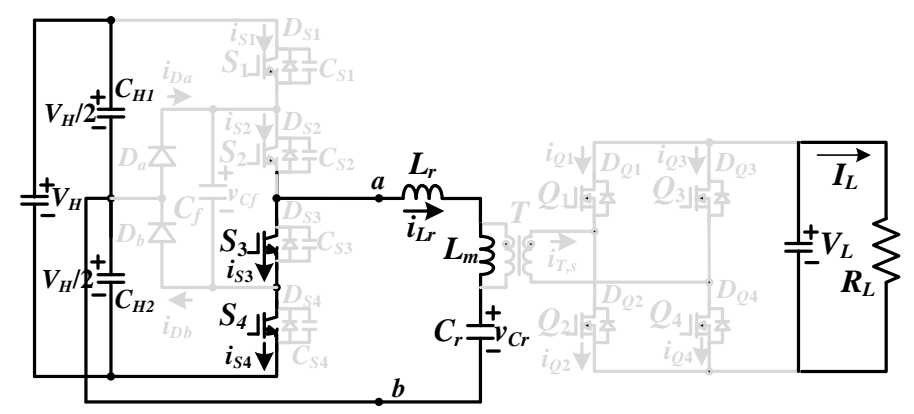

(e)

Figure 3. Cont. 


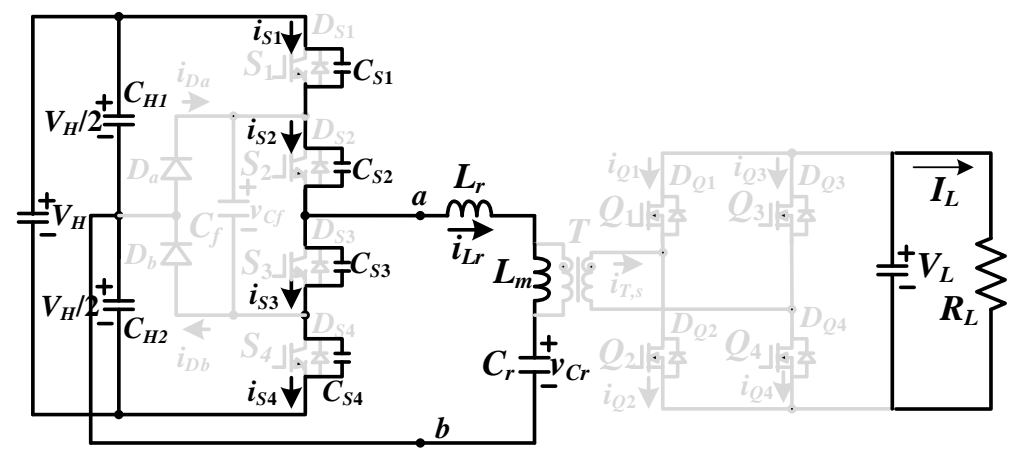

$(\mathbf{f})$

Figure 3. The corresponding equivalent circuits related to six operating steps for forward power operation (a) step 1 circuit (b) step 2 circuit (c) step 3 circuit (d) step 4 circuit (e) step 5 circuit (f) step 6 circuit.

Step $1\left(t_{0} \leq t<t_{1}\right)$ : At $t<t_{0}, i_{L r}<0$. Thus, $i_{L r}$ discharges $C_{S 1}$ and $C_{S 2}$ are discharged. At $t_{0}$, $v_{C S 1}=v_{C S 2}=0$. Thus, $D_{S 1}$ and $D_{S 2}$ are conducting due to $i_{L r}<0$. The ZVS operation of $S_{1}$ and $S_{2}$ can be achieved after time $t_{0}$. If $i_{L r}<0, D_{b}$ is forward biased. The leg voltage $v_{a b}=v_{C f}=v_{C S 3}=v_{C S 4}=V_{H} / 2$. Since $i_{L r}>i_{L m}, Q_{1}$ and $Q_{4}$ turn on to conduct the secondary-side current. When $i_{L r}$ increases and $i_{L r}$ $>0, D_{b}$ becomes off. In this step, the magnetizing voltage $v_{L m}$ is equal to $n V_{L}$, where $n=n_{p} / n_{s}$ is the transformer turns ratio, and $i_{L m}$ increases. The ripple current $\Delta i_{L m}$ in step 1 is equal to $n V_{L} \Delta t_{01} / L_{m}$ where $\Delta t_{01}=t_{1}-t_{0}$. The resonant frequency in step 1 is $f_{r}=1 /\left(2 \pi \sqrt{L_{r} C_{r}}\right)$.

Step $2\left(t_{1} \leq t<t_{2}\right)$ : If $f_{s w}<f_{r}, i_{Q 1}$ and $i_{Q 4}$ will decrease to zero ampere at $t_{1}$. Thus, $Q_{1}$ and $Q_{4}$ can turn off after time $t_{1}$. In step 2, the leg voltage $v_{a b}=V_{H} / 2$ and $L_{r}, L_{m}$ and $C_{r}$ are resonant.

Step $3\left(t_{2} \leq t<t_{3}\right)$ : At $t_{2}, S_{1}$ and $S_{2}$ turn off. The positive current $i_{L r}\left(t_{2}\right)$ will charge $C_{S 1}$ and $C_{S 2}$. On the other hand, $C_{S 3}$ and $C_{S 4}$ are discharged in this step. The ZVS operation of $S_{3}$ and $S_{4}$ is expressed in Equation (1).

$$
i_{L m, p} \geq \frac{V_{H}}{2} \sqrt{\frac{C_{S}}{L_{r}}}
$$

where $i_{L m, p}$ is the peak current on $L_{m}$ and $C_{S}=C_{S 1}=\ldots=C_{S 4}$. The peak current $i_{L m, p}$ is calculated from Equation (2).

$$
i_{L m, p}=\frac{\Delta i_{L m}}{2} \approx \frac{n V_{L} T_{s w}}{4 L_{m}}
$$

The dead time $t_{d}$ between $S_{3}$ and $S_{1}$ (or $S_{4}$ and $S_{2}$ ) is approximately expressed in Equation (3).

$$
t_{d}>\frac{C_{S} V_{H}}{i_{L m, p}}=\frac{4 L_{m} C_{S} V_{H}}{n V_{L} T_{s w}}
$$

Therefore, the maximum magnetizing inductance is derived in Equation (4).

$$
L_{m} \leq \frac{n V_{L} t_{d} T_{s w}}{4 C_{S} V_{H}}
$$

Step $4\left(t_{3} \leq t<t_{4}\right)$ : At $t_{3}, v_{C S 3}=v_{C S 4}=0$. Since $i_{L r}\left(t_{3}\right)$ is positive, $D_{S 3}$ and $D_{S 4}$ are conducting. Power devices $S_{3}$ and $S_{4}$ can turn on after $t_{3}$ under zero voltage condition. Since $i_{L r}\left(t_{3}\right)>0, D_{a}$ is forward biased. The leg voltage $v_{a b}=-V_{H} / 2$ and $v_{C f}=v_{C S 1}=v_{C S 2}=V_{H} / 2$. When $i_{L r}$ decreases and $i_{L r}$ $<0, D_{a}$ becomes off. On the secondary side, $i_{Q_{2}}\left(t_{3}\right)<0$ and $i_{Q 3}\left(t_{3}\right)<0$. Therefore, $Q_{2}$ and $Q_{3}$ turn on to conduct the secondary-side current, the primary-side voltage $v_{L m}=-n V_{L}$ and $i_{L m}$ decreases.

Step $5\left(t_{4} \leq t<t_{5}\right)$ : The secondary-side switch currents $i_{Q 2}=i_{Q 3}=0$ at $t_{4}$. Then, $Q_{2}$ and $Q_{3}$ turn off. In this step, $v_{a b}=-V_{H} / 2$ and $L_{r}, L_{m}$ and $C_{r}$ are resonant. 
Step $6\left(t_{5} \leq t<T_{s w}+t_{0}\right)$ : At $t_{5}, S_{3}$ and $S_{4}$ turn off. In this step, $i_{L r}\left(t_{5}\right)<0$ and $v_{C S 1}$ and $v_{C S 2}$ decrease. The ZVS condition of $S_{2}$ and $S_{1}$ is the same as $S_{4}$ and $S_{3}$ in Equation (1). The step 6 is ended at time $T_{s w}+t_{0}$.

The $L L C$ resonant circuit is controlled to achieve ZVS operation and the bidirectional power operation. The resonant circuit is based on the fundamental frequency analysis to achieve load voltage regulation. According to the switching status of power devices $S_{1} \sim S_{4}$ and $Q_{1} \sim Q_{4}$, the voltage values $V_{H} / 2$ and $-V_{H} / 2$ are observed on $v_{a b}$, and the other voltage values $n V_{L}$ and $-n V_{L}$ are generated on the magnetizing inductor voltage $v_{L m} . L_{r}, C_{r}, L_{m}$ and $R_{a c, L}$ operate as a filter to suppress the high order harmonics. The root mean square $(r m s)$ voltages at the fundamental frequency for input and output sides are $v_{a b, r m s}=\sqrt{2} V_{H} / \pi$ and $v_{L m, r m s}=2 \sqrt{2} n V_{L} / \pi$. Based on the power balance between the primary-side and the secondary-side of transformer, the primary-side load resistance is expressed as $R_{a c, L}=8 n^{2} R_{L} / \pi^{2}$. The transfer function $G_{H_{-} L}(s)$ between the output and input sides in Figure 2a is obtained as:

$$
\begin{gathered}
G_{H_{-} L}(s)=\frac{v_{L m, r m s}(s)}{v_{a b, r m s}(s)}=\frac{\frac{s L_{m} R_{a c, L}}{s L_{m}+R_{a c, L}}}{\frac{s L_{m} R_{a c, L}}{s L_{m}+R_{a c, L}}+s L_{r}+\frac{1}{s C_{r}}} \\
\left|G_{H_{-} L}(F)\right|=\frac{K_{1} F^{2}}{\sqrt{\left[F^{2}\left(K_{1}+1\right)-1\right]^{2}+\left[Q_{1} K_{1} F\left(F^{2}-1\right)\right]^{2}}}
\end{gathered}
$$

where $F=f_{s w} / f_{r}, f_{r}=1 /\left(2 \pi \sqrt{L_{r} C_{r}}\right), K_{1}=L_{m} / L_{r}$ and $Q_{1}=\sqrt{L_{r} / C_{r}} / R_{a c, L}$. From the given input voltage $V_{H}$, the output voltage $V_{L}$ and the circuit parameters $L_{r}, C_{r}, L_{m}$ and $R_{L}$, the switching frequency is obtained from Equation (6).

For reverse power flow shown in Figure 1c, the developed converter transfers power from $V_{L}$ terminal to $V_{H}$ terminal. $S_{a c}$ is turned on and $L_{b}, L_{r}$ and $C_{r}$ are operated as a series resonant circuit to achieve voltage $V_{H}$ regulation. Power devices $Q_{1} \sim Q_{4}$ are controlled with PFM scheme and $D_{S 1} \sim D_{S 4}$ work as a full-wave rectifier. When $\left|i_{L r}\right|>\left|i_{L b}\right|, D_{S 1}$ and $D_{S 2}$ or $D_{S 3}$ and $D_{S 4}$ are conducting. Since the $L L C$ resonant circuit by $L_{r}, C_{r}$ and $L_{b}$ is operated at the inductive load, power devices $Q_{1} \sim Q_{4}$ are operated at the zero-voltage turn-on switching. Figure 4 a shows the ac equivalent resonant circuit at reverse power flow operation. $L_{b}$ and $R_{a c, H}$ are the parallel inductance and ac equivalent resistance. Figure $4 \mathrm{~b}$ gives the main PWM waveforms and Figure 5 demonstrates the corresponding equivalent circuits at the reverse power flow operation.

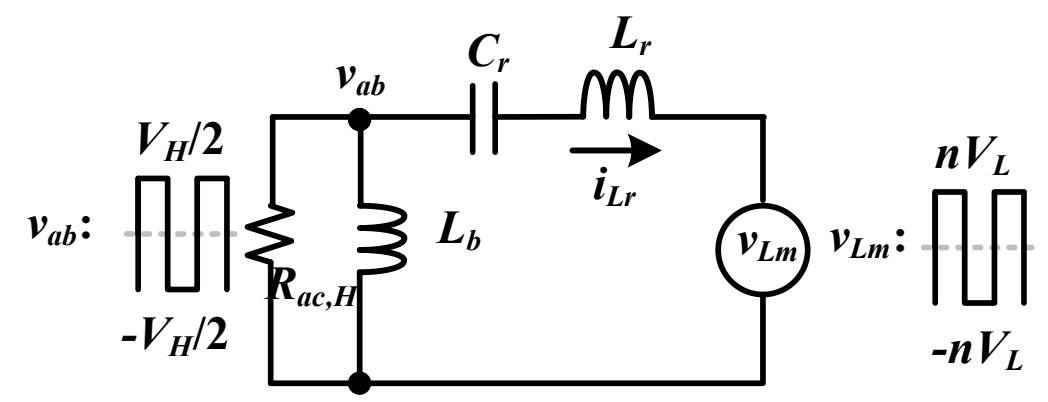

(a)

Figure 4. Cont. 


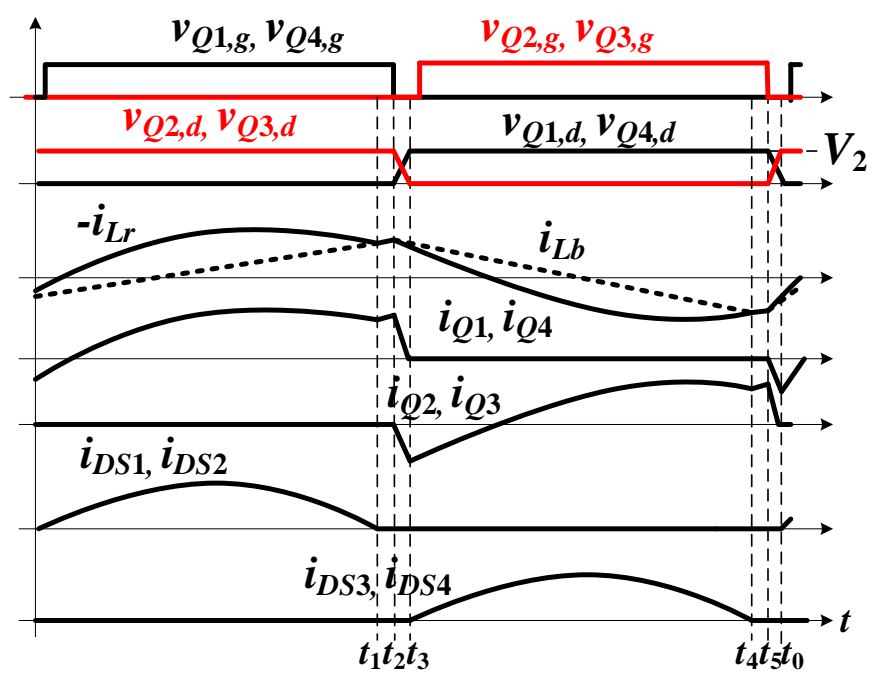

(b)

Figure 4. The proposed circuit operated at reverse power flow (a) the equivalent $L L C$ resonant circuit (b) PWM waveforms.

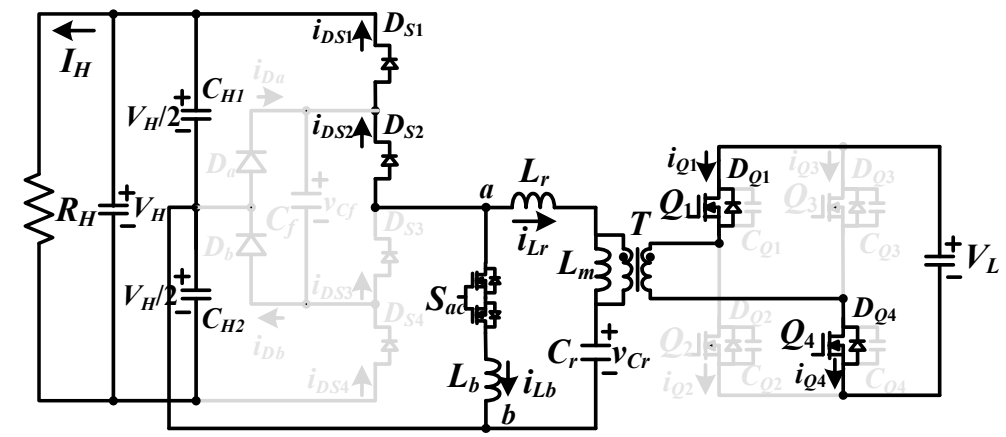

(a)

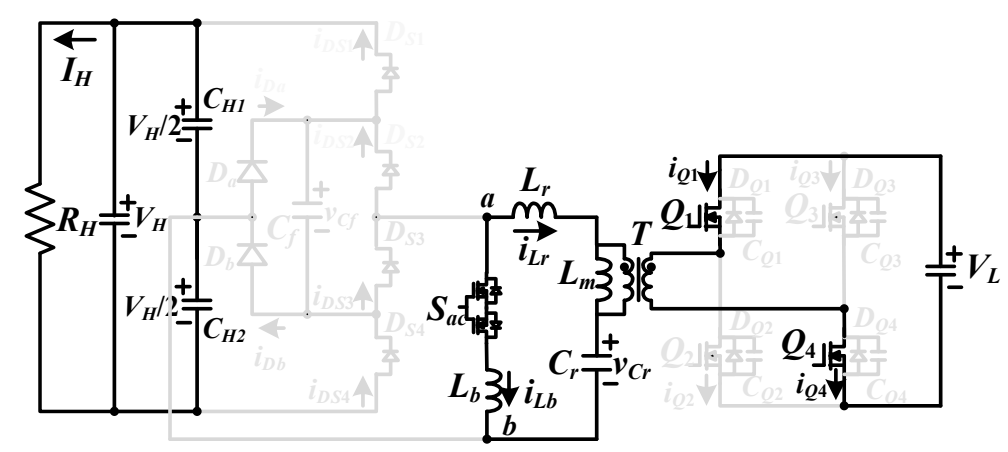

(b)

Figure 5. Cont. 


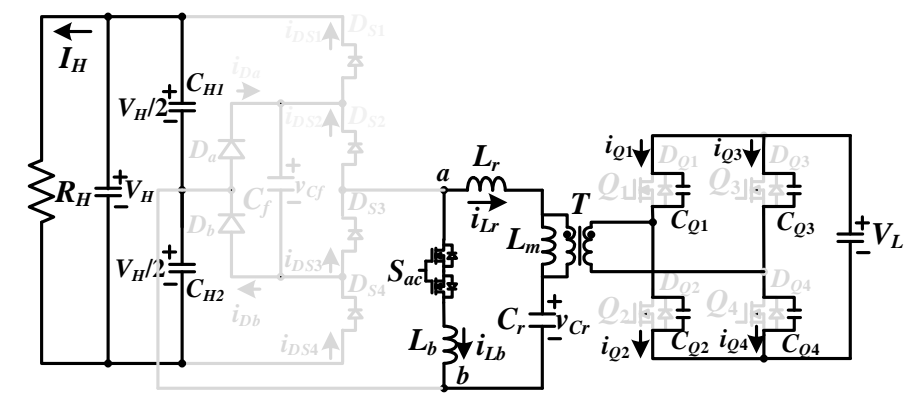

(c)

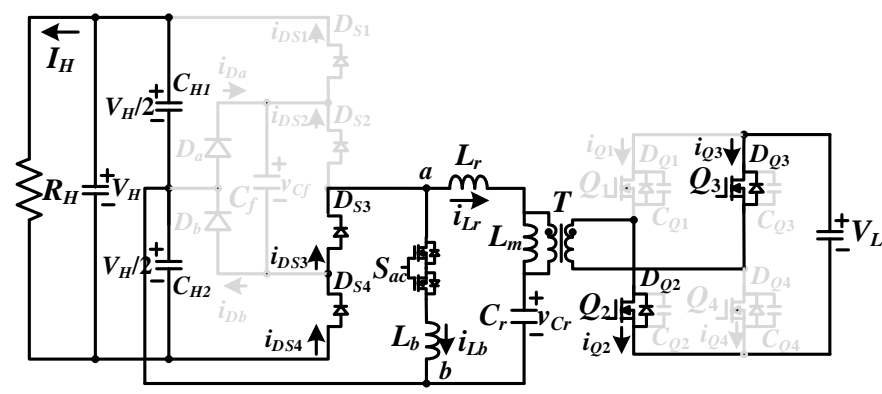

(d)

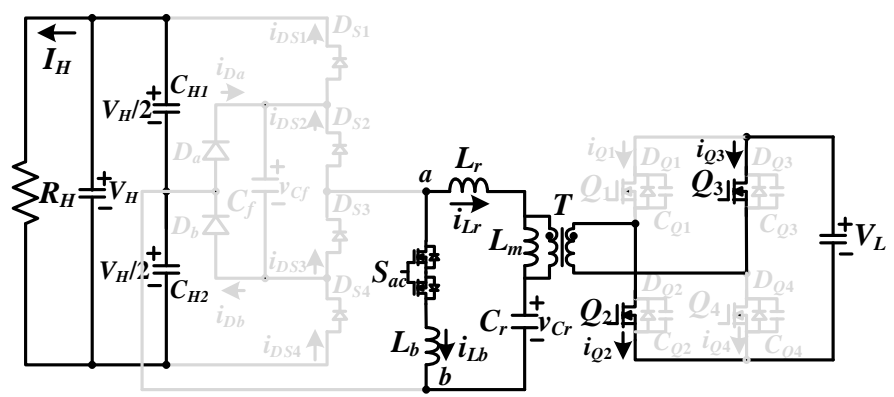

(e)

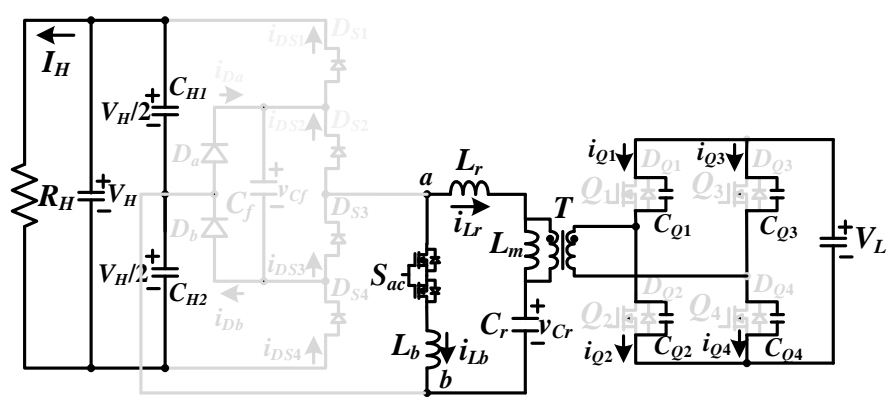

(f)

Figure 5. The corresponding equivalent circuits related to six operating steps under backward power transfer (a) step 1 circuit (b) step 2 circuit (c) step 3 circuit (d) step 4 circuit (e) step 5 circuit (f) step 6 circuit. 
Step $1\left(t_{0} \leq t<t_{1}\right)$ : This step starts at $t_{0}$ when $v_{C Q 4}=v_{C Q 1}=0$. Then, the $D_{Q 4}$ and $D_{Q 1}$ conduct and $v_{Q 2, d s}=v_{Q 3, d s}=V_{L}$. Due to $D_{Q 1}$ and $D_{Q 4}$ are conducting, $v_{Q 4, d s}$ and $v_{Q 1, d s}=0$ and $Q_{1}$ and $Q_{4}$ can turn on under zero voltage. Due to $i_{L r}\left(t_{0}\right)+i_{L b}\left(t_{0}\right)<0, D_{S 1}$ and $D_{S 2}$ are forward biased, $C_{H 1}$ is charged, $v_{L m}=n V_{L}, v_{a b}=V_{H} / 2$ and $i_{L m}$ and $i_{L b}$ both increase. Before switches $Q_{1}$ and $Q_{4}$ turn off, $i_{D S 1}$ and $i_{D S 2}$ will decrease to zero if $f_{s w}<f_{r}=1 / 2 \pi \sqrt{C_{r} L_{r}}$.

Step $2\left(t_{1} \leq t<t_{2}\right)$ : At time $t_{1}, i_{D S 2}=i_{D S 1}=0$ and $D_{S 2}$ and $D_{S 1}$ are off. $L_{r}, L_{b}$, and $C_{r}$ are series resonant at frequency $f_{p}=1 / 2 \pi \sqrt{C_{r}\left(L_{b}+L_{r}\right)}$.

Step $3\left(t_{2} \leq t<t_{3}\right): Q_{4}$ and $Q_{1}$ turn off at $t_{2} . C_{Q 2}$ and $C_{Q 3}$ are discharged in step 3. The ZVS condition of $Q_{3}$ and $Q_{2}$ are obtained in Equation (7).

$$
\left(L_{b}+L_{r}\right) i_{L b, p}^{2}+L_{m} i_{L m, p}^{2} \geq 2 C_{Q} V_{L}^{2}
$$

where $C_{Q}=C_{Q 1}=. .=C_{Q 4}, i_{L m, p} \approx n V_{L} /\left(4 L_{m} f_{s w}\right)$ and $i_{L b, p} \approx V_{H} /\left(8 L_{b} f_{s w}\right)$. At $t_{3}, v_{C Q 3}\left(t_{3}\right)=v_{C Q 2}\left(t_{3}\right)=0$. The time interval $\Delta t_{23}$ is expressed in Equation (8).

$$
\Delta t_{23} \approx \frac{2 V_{L} C_{Q}}{n\left[i_{L m, p}+i_{L b, p}\right]}=\frac{16 L_{m} L_{b} f_{s w} V_{L} C_{Q}}{n\left(2 n L_{b} V_{L}+L_{m} V_{H}\right)} \leq t_{d}
$$

where $t_{d}$ is dead time between $Q_{4}$ and $Q_{3}$ or $Q_{2}$ and $Q_{1}$.

Step $4\left(t_{3} \leq t<t_{4}\right)$ : Step 4 starts at $t_{3}$ when $v_{\mathrm{CQ} 2}=v_{\mathrm{CQ} 3}=0$. Therefore, $D_{\mathrm{Q} 3}$ and $D_{\mathrm{Q} 2}$ conduct and $Q_{3}$ and $Q_{2}$ can turn on under zero voltage. In step $4, D_{S 3}$ and $D_{S 4}$ conduct, $v_{a b}=-V_{H} / 2, v_{L m}=-n V_{L}$, and $i_{L m}$ and $i_{L b}$ both decrease.

Step $5\left(t_{4} \leq t<t_{5}\right): i_{D S 3}=i_{D S 4}=0$ at $t_{4}$. In this step, $Q_{2}$ and $Q_{3}$ are still in the on state so that $v_{L m}=-n V_{L} . L_{b}, C_{r}$ and $L_{r}$ are series resonant.

Step $6\left(t_{5} \leq t<T_{s w}+t_{0}\right): Q_{2}$ and $Q_{3}$ turn off at $t_{5}$. Then, $C_{Q 1}$ and $C_{Q 4}$ are discharged and $v_{C Q 1}=v_{C Q 4}=0$ at $t_{s w}+t_{0}$.

The proposed converter has the similar operation principle for both forward and reverse power operation. For the reverse power operation, $Q_{1} \sim Q_{4}$ are controlled as main power switches. $D_{S 1} \sim D_{S 4}$ are operated as diode rectifier to regulate voltage $V_{H}$. The resonant circuit including $L_{b}, L_{r}$ and $C_{r}$ is operated as a filter to suppress high order harmonics. The input $r m s$ voltage at fundamental frequency (Figure 4a) is calculated as $v_{L m, r m s}=2 \sqrt{2} n V_{L} / \pi$ and the ac equivalent resistance at high voltage side is $R_{a c, H}=2 R_{H} / \pi^{2}$. The rms voltage on $v_{a b}$ is expressed as $v_{a b, r m s}=\sqrt{2} V_{H} / \pi$. Components $R_{a c, H}, L_{b}$, $L_{r}$ and $C_{r}$ are resonant. The transfer function $G_{L_{-} H}(s)$ and gain $\left|G_{L_{-} H}(s)\right|$ are calculated in Equations (9) and (10), respectively.

$$
\begin{gathered}
G_{L_{-} H}(s)=\frac{v_{a b, r m s}(s)}{v_{L m, r m s}(s)}=\frac{\frac{s L_{b} R_{a c, H}}{s L_{b}+R_{a c, H}}}{\frac{s L_{b} R_{a c, H}}{s L_{b}+R_{a c, H}}+\frac{1}{s C_{r}}+s L_{r}} \\
\left|G_{L_{-} H}(F)\right|=\frac{K_{2} F^{2}}{\sqrt{\left[\left(F^{2}-1\right) Q_{2} K_{2} F\right]^{2}+\left[F^{2}\left(K_{2}+1\right)-1\right]^{2}}}
\end{gathered}
$$

where $F=f_{s w} / f_{r}, f_{r}=1 /\left(2 \pi \sqrt{L_{r} C_{r}}\right), K_{2}=L_{b} / L_{r}$ and $Q_{2}=\sqrt{L_{r} / C_{r}} / R_{a c, H}$. From the given input voltage $V_{H}$, output voltage $V_{L}$ and the circuit parameters $L_{r}, C_{r}, L_{b}$ and $R_{H}$, the switching frequency is obtained from Equation (10).

\section{Circuit Parameters and Test Results}

For forward power transfer, the input and output voltages are $V_{H}=750 \mathrm{~V}$ to $800 \mathrm{~V}$ and $V_{L}=48 \mathrm{~V}$. The rated power is $1440 \mathrm{~W}\left(v_{L}=48 \mathrm{~V}\right.$ and $\left.I_{L}=30 \mathrm{~A}\right)$. For reverse power transfer, the input and output voltages are $V_{L}=36 \mathrm{~V}$ to $52 \mathrm{~V}$ and $V_{H}=800 \mathrm{~V}$. The transfer functions in Equations (6) and (10) for forward and backward power transfer operations are similar. Thus, the circuit parameters design operated at forward power flow is presented in this section. The dc voltage gain under $V_{H}=800 \mathrm{~V}$ 
input and $V_{L, \max }=52 \mathrm{~V}$ output is designed to be unity. The transformer turns ratio is calculated in Equation (11).

$$
n=\left|G_{H \_L}\right| \times \frac{V_{H, \max }}{2 V_{L, \max }} \approx 7.7
$$

In the prototype circuit, the selected primary and secondary turns are $n_{H}=48$ and $n_{L}=6$. Thus, the actual transformer turns ratio is $n=n_{H} / n_{L}=8$. With the adopted turns ratio, the actual maximum and minimum voltage gains at $V_{L, n o m}=48 \mathrm{~V}$ condition are given in Equations (12) and (13).

$$
\begin{gathered}
\left|G_{H \_}\right|_{\text {max }}=\frac{2 n V_{L, n o m}}{V_{H, \text { min }}} \approx 1.024 \\
\left|G_{H \_L}\right|_{\text {min }}=\frac{2 n V_{L, n o m}}{V_{H, \text { max }}} \approx 0.96
\end{gathered}
$$

The control parameters $K_{1}$ and $Q_{1}$ can be selected at full load $P_{L, f u l l}$ and minimum input voltage $V_{H, \min }$ conditions. To reduce circulating current, the inductor ratio $K_{1}=10$ is used in this prototype circuit. For $Q_{1}=0.38$ and $K_{1}=10$, it can obtain the peak gain of $\left|G_{H_{-} L}(\mathrm{~s})\right|$ is 1.13 . The ac equivalent resistance $R_{a c, L}$ at the rated power is obtained in Equation (14).

$$
R_{a c, L}=\frac{8 n^{2}}{\pi^{2}} R_{L}=\frac{8 \times(48 / 6)^{2}}{3.14159^{2}} \times \frac{48}{30} \approx 83 \Omega
$$

The circuit parameters $C_{r}=1 / 2 \pi Q_{1} f_{r} R_{a c, L} \approx 50 \mathrm{nF}$ and $L_{r}=1 /\left(2 \pi f_{r}\right)^{2} C_{r} \approx 50 \mu \mathrm{H}$ under $f_{r}=100 \mathrm{kHz}$. The actual resonant inductance and capacitance are $C_{r}=47 \mathrm{nF}$ and $L_{r}=54 \mu \mathrm{H}$ and the magnetizing inductance $L_{m}=K_{1} L_{r}=540 \mu \mathrm{H}$. The theoretical primary rms current is calculated as:

$$
I_{\text {pri,rms }}=\frac{\pi I_{O}}{2 \sqrt{2} n} \approx 4.2 \mathrm{~A}
$$

The theoretical minimum switching frequency is obtained as $f_{s w, \min }=1 / 2 \pi \sqrt{C_{r}\left(L_{r}+L_{m}\right)} \approx 30 \mathrm{kHz}$. The minimum switching frequency will result in the maximum $r m s$ magnetizing current.

$$
I_{L m, r m s}=\frac{1}{2 \sqrt{3}} \frac{n V_{L}}{4 f_{s w, \min } L_{m}} \approx 1.7 \mathrm{~A}
$$

Therefore, the rms resonant inductor current is obtained in Equation (17).

$$
I_{L r, r m s}=\sqrt{I_{L m, r m s}^{2}+I_{p r i, r m s}^{2}} \approx 4.53 \mathrm{~A}
$$

The flying capacitor $C_{f}$ is used to realize voltage balance of $C_{H 1}$ and $C_{H 2}$ so that $V_{C H 1}=V_{C H 2}=V_{H} / 2$. The theoretical voltage stresses of power semiconductors can be calculated as $v_{S 1, \text { stress }}=. .=v_{S 4, \text { stress }}$ $=V_{H, \text { max }} / 2=400 \mathrm{~V}$ and $v_{Q 1, \text { stress }}=. .=v_{Q 4, \text { stress }}=V_{L, \max }=52 \mathrm{~V}$. The switch currents approximate $I_{S 1, r m s}=. .=I_{S 4, r m s} \approx I_{L r, r m s} / \sqrt{2} \approx 3.2 \mathrm{~A}$ and $I_{Q 1, r m s}=. .=I_{Q 4, r m s} \approx \pi I_{o} / 4 \approx 23.6 \mathrm{~A}$. Power devices $S_{1} \sim S_{4}$ are implemented using IRG4PC40W with $600 \mathrm{~V} / 20 \mathrm{~A}$ rating. Power switches $Q_{1} \sim Q_{4}$ are implemented using IRFB3307 with $75 \mathrm{~V} / 150$ A rating. $S_{a c}$ is implemented using two G20N50C with $500 \mathrm{~V} / 20 \mathrm{~A}$ rating. The parallel inductor $L_{b}$ is selected as $230 \mu \mathrm{H}$ and $K_{2}=L_{b} / L_{r}=4.25$ under reverse power flow operation. The clamp diodes $D_{a}$ and $D_{b}$ are implemented with ultrafast recovery diodes HFA15TB60PBF with $600 \mathrm{~V} / 15 \mathrm{~A}$ rating. The other circuit parameters used in the prototype are $C_{H 1}=C_{H 2}=330 \mu \mathrm{F} / 400 \mathrm{~V}, C_{f}=2.2 \mu \mathrm{F} / 630 \mathrm{~V}$ and $C_{L}=4400 \mu \mathrm{F} / 100 \mathrm{~V}$. The parameters and specifications used in the laboratory prototype are given in Table 1. 
Table 1. Parameters and specifications of the presented converter.

\begin{tabular}{cc}
\hline Items & Parameter \\
\hline High voltage $V_{H}$ & $750 \mathrm{~V} \sim 800 \mathrm{~V}$ \\
\hline Low voltage $V_{L}$ & $48 \mathrm{~V}$ \\
\hline Rated power $P_{o}$ & $1440 \mathrm{~W}$ \\
\hline Resonant frequency $f_{r}$ & $100 \mathrm{kHz}$ \\
\hline High-side capacitances $C_{H 1}, C_{H 2}$ & $330 \mu \mathrm{F} / 400 \mathrm{~V}$ \\
\hline Low-side capacitance $C_{L}$ & $4400 \mu \mathrm{F} / 100 \mathrm{~V}$ \\
\hline Resonant capacitance $C_{r}$ & $47 \mathrm{nF}$ \\
\hline Flying capacitance $C_{f}$ & $2.2 \mu \mathrm{F}$ \\
\hline Resonant inductance $L_{r}$ & $54 \mu \mathrm{H}$ \\
\hline Parallel inductance $L_{b}$ & $230 \mu \mathrm{H}$ \\
\hline Power switches $S_{1} \sim S_{4}$ & IRG4PC40W $(600 \mathrm{~V} / 20 \mathrm{~A})$ \\
\hline Power switches $Q_{1} \sim Q_{4}$ & IRFB3307 $(75 \mathrm{~V} / 150 \mathrm{~A})$ \\
\hline Power switch $S_{a c}$ & G20N50C $(500 \mathrm{~V} / 20 \mathrm{~A})$ \\
\hline Clamp diodes $D_{a}, D_{b}$ & HFA15TB60PBF $(600 \mathrm{~V} / 15 \mathrm{~A})$ \\
\hline Winding turns of $T: n_{H}, n_{L}$ & 48,6 \\
\hline Magnetizing inductance $L_{m}$ & $540 \mu \mathrm{H}$ \\
\hline
\end{tabular}

Figures 6-10 provide the test results for forward power operation and Figures 11-14 provide the measured waveforms for reverse power operation. The PWM signals of $S_{1}-S_{4}$ at $100 \%$ load are presented in Figure 6. $S_{1}\left(S_{3}\right)$ and $S_{2}\left(S_{4}\right)$ have the same gate-to-source voltage signals. The converter at $V_{H}=750 \mathrm{~V}$ input has less switching frequency than $V_{H}=800 \mathrm{~V}$ input condition. Figure 7 gives the experimental results of leg voltage $v_{a b}, i_{L r}$ and $v_{C r}$ at $100 \%$ load. It can be seen that the measured waveforms $i_{L r}$ and $v_{C r}$ are almost the sinusoidal waves due to $f_{s w}$ close to $f_{r}$ for both $750 \mathrm{~V}$ and $800 \mathrm{~V}$ inputs. Figure 8 shows the experimental results of $V_{C H 1}, V_{C H 2}, V_{C f}, V_{D a}$ and $V_{D b}$. The dc voltage differences between $V_{\mathrm{CH} 1}, V_{\mathrm{CH} 2}$ and $V_{C f}$ are about $5 \mathrm{~V}$. Figure 9 demonstrates the switch currents of $Q_{1}-Q_{4}$ at $100 \%$ load. Figure 10 illustrates the PWM waveforms of $S_{1}-S_{4}$ at $20 \%$ load. It can observe that $S_{1}-S_{4}$ all turn on under ZVS at $20 \%$ load. Figure 11 gives the PWM signals of $Q_{1} \sim Q_{4}$ under backward power operation and different input voltages. Power devices $Q_{1}\left(Q_{2}\right)$ and $Q_{4}\left(Q_{3}\right)$ have the same gate-to-source voltage signals. Figure 12 illustrates the measured results of $i_{L r}, i_{L b}$ and $v_{C r}$ under for reverse power operation. The parallel inductor current $i_{L b}$ is similar to the magnetizing current on conventional $L L C$ resonant converter to achieve voltage step-up capability. Figure 13 shows the measured capacitor voltages $V_{C f}, V_{C H 1}$ and $V_{C H 2}$ on the high voltage side. These three voltages $V_{C H 1}$, $V_{\mathrm{CH} 2}$ and $V_{C f}$ are almost balanced with about $7 \mathrm{~V}$ voltage difference. Figure 14 gives the measured PWM waveforms of $Q_{1} \sim Q_{4}$ under $20 \%$ load. It can observe that $Q_{1}-Q_{4}$ can turn on under zero voltage at $20 \%$ load. For forward power operation (buck mode), the measured circuit efficiencies are $89.7 \%$ at $20 \%$ load, $92.1 \%$ at $50 \%$ load and $91.8 \%$ at $100 \%$ load under $800 \mathrm{~V}$ input. For reverse power operation (boost mode), the measured circuit efficiencies are $86.3 \%$ at $20 \%$ load, $89.4 \%$ at $50 \%$ load and $88.9 \%$ at $100 \%$ load under $40 \mathrm{~V}$ input case. Figure $15 \mathrm{a}$ gives the picture of the prototype circuit and the experimental setup is given in Figure 15b. 


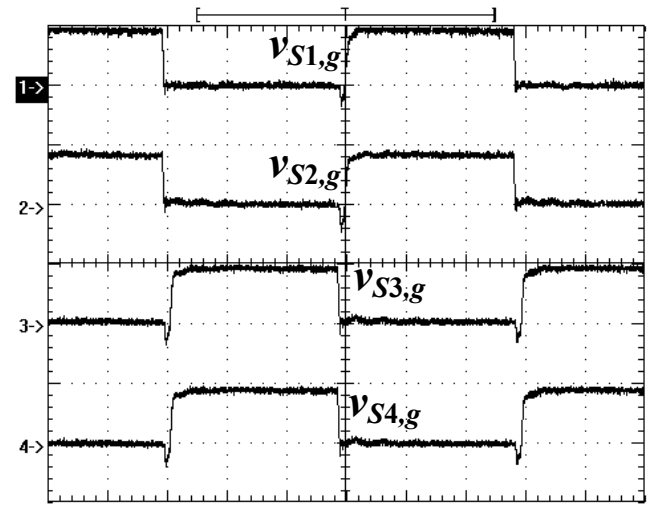

(a)

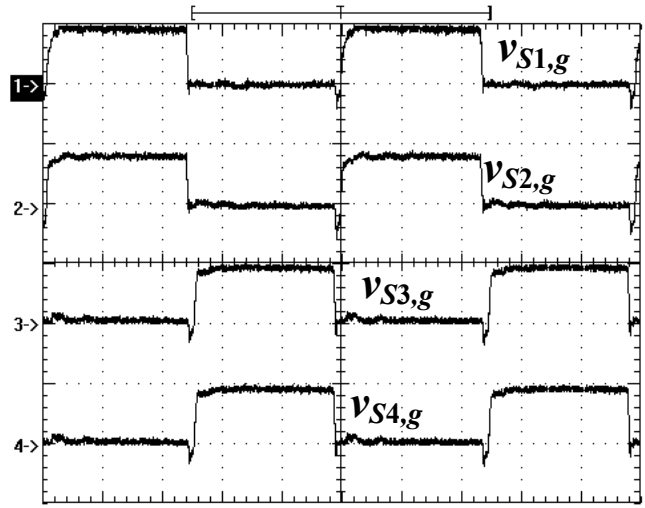

(b)

Figure 6. Measured PWM signals of $S_{1}-S_{4}$ at full load (a) $V_{H}=750 \mathrm{~V}$ (b) $V_{H}=800 \mathrm{~V}\left(v_{S 1, g} \sim v_{S 4, g}\right.$ : $10 \mathrm{~V} /$ div; time: $2 \mu \mathrm{s})$.

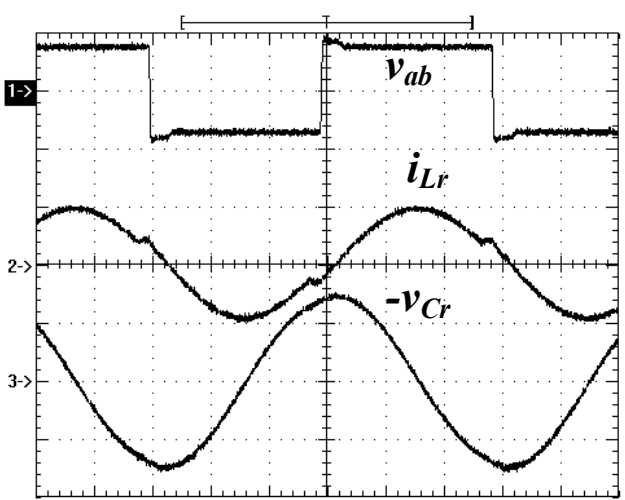

(a)

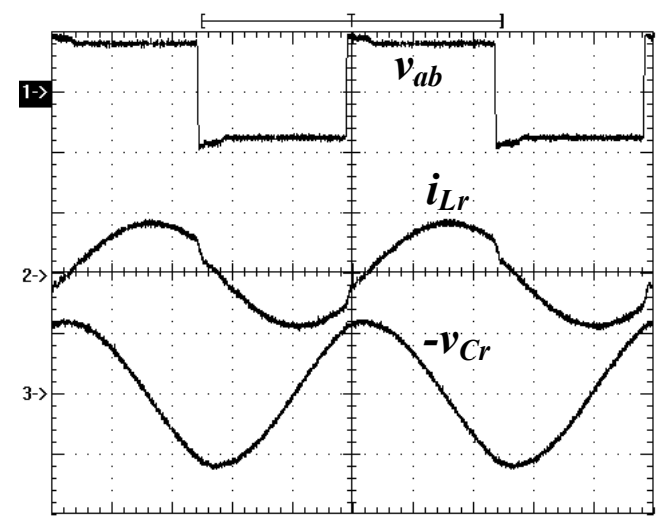

(b)

Figure 7. Measured results of $v_{a b}, i_{L r}$ and $v_{C r}$ at full load (a) $V_{H}=750 \mathrm{~V}(\mathbf{b}) V_{H}=800 \mathrm{~V}\left(v_{a b}: 500 \mathrm{~V} / \mathrm{div}\right.$; $i_{L r}: 10 \mathrm{~A} / \mathrm{div} ; v_{C r}: 200 \mathrm{~V} / \mathrm{div}$; time: $\left.2 \mu \mathrm{s}\right)$.

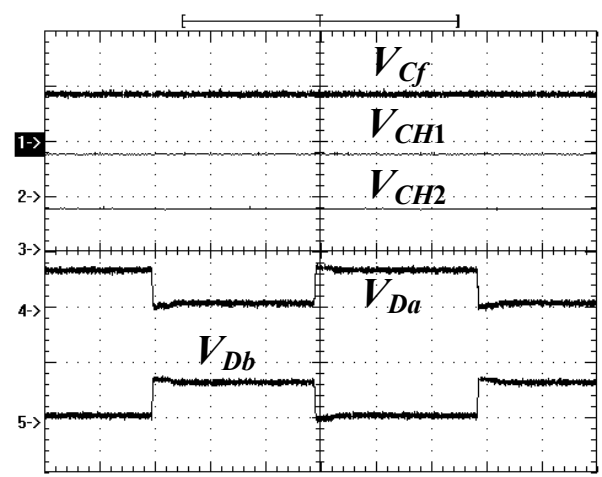

(a)

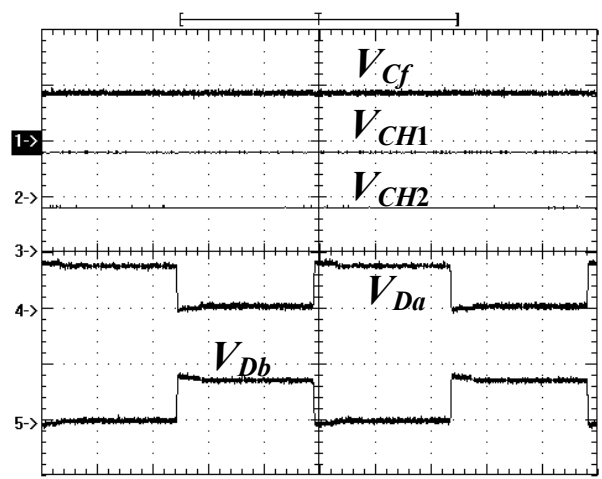

(b)

Figure 8. Measured results of $V_{C f}, V_{C H 1}, V_{C H 2}, V_{D a}$ and $V_{D b}$ at full load (a) $V_{H}=750 \mathrm{~V}$ (b) $V_{H}=800 \mathrm{~V}$ $\left(v_{C f}, V_{C H 1}, V_{C H 2}, V_{D a}, V_{D b}: 500 \mathrm{~V} /\right.$ div; time: $\left.2 \mu \mathrm{s}\right)$. 


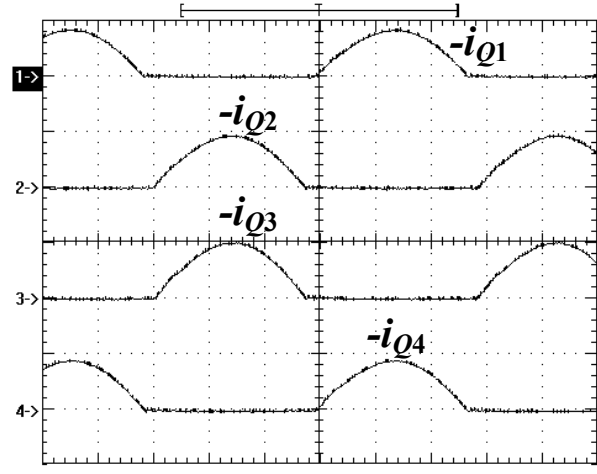

(a)

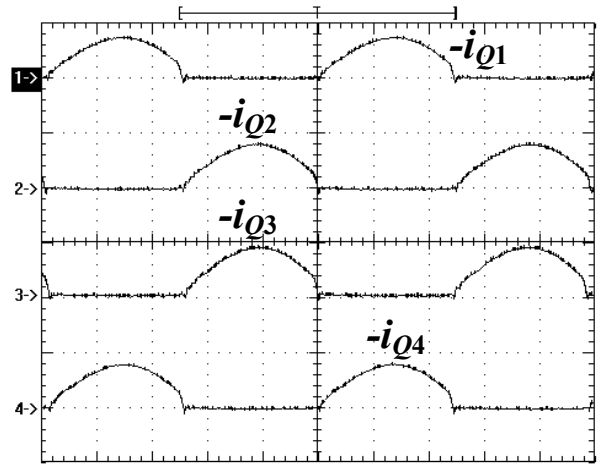

(b)

Figure 9. Measured switch currents of $Q_{1}-Q_{4}$ under full load (a) $V_{H}=750 \mathrm{~V}$ (b) $V_{H}=800 \mathrm{~V}\left(-i_{Q 1} \sim-i_{Q 4}\right.$ : $50 \mathrm{~A} /$ div; time: $2 \mu \mathrm{s})$.

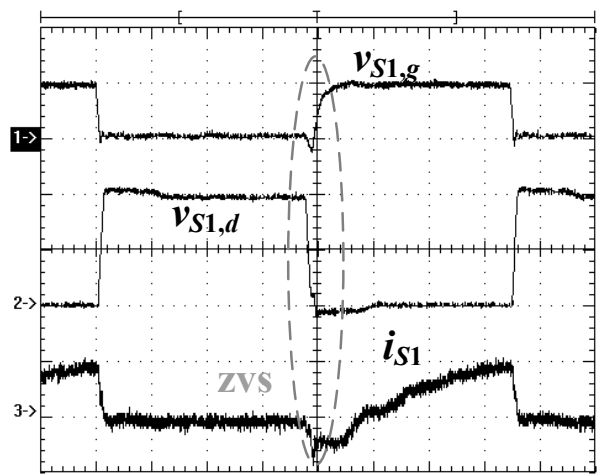

(a)

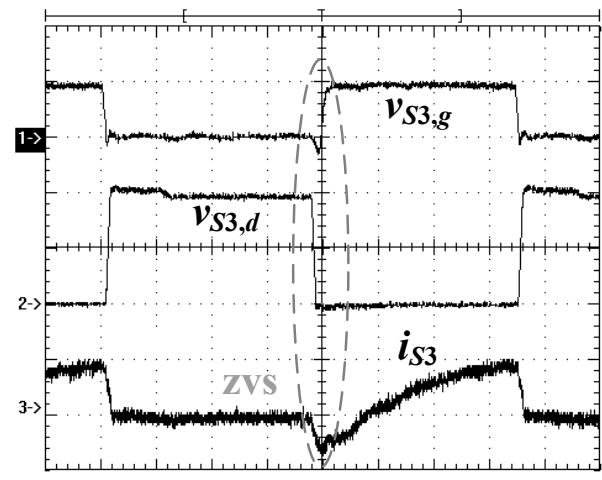

(c)

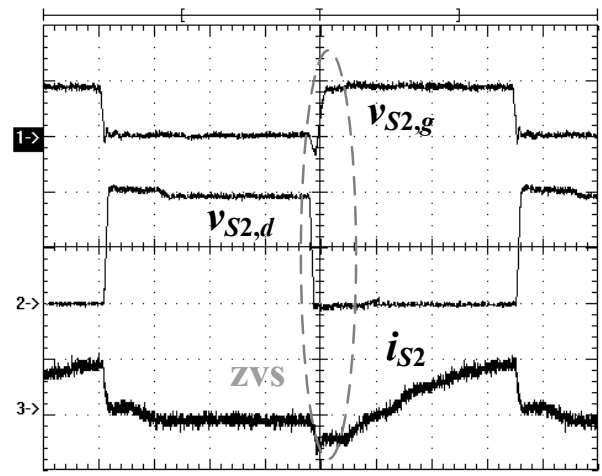

(b)

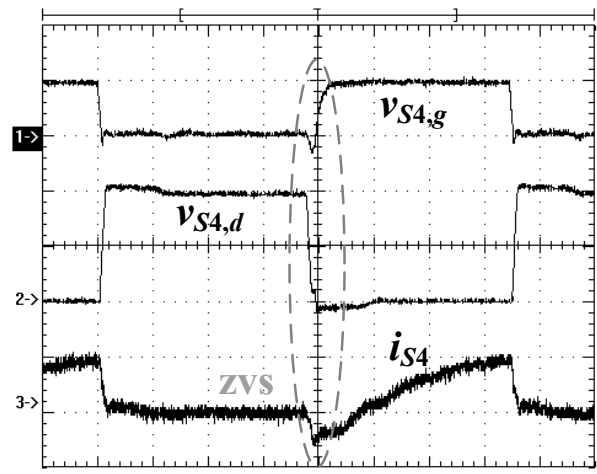

(d)

Figure 10. Measured PWM waveforms of $S_{1}-S_{4}$ at $20 \%$ load (a) $S_{1}$ waveforms (b) $S_{2}$ waveform (c) $S_{3}$ waveform (d) $S_{4}$ waveform $\left(v_{S 1, g}-v_{S 4, g}: 10 \mathrm{~V} /\right.$ div; $v_{S 1, d}-v_{S 4, d}: 200 \mathrm{~V} /$ div; $i_{S 1} \sim i_{S 4}: 2 \mathrm{~A} /$ div; time: $\left.1 \mu \mathrm{s}\right)$. 


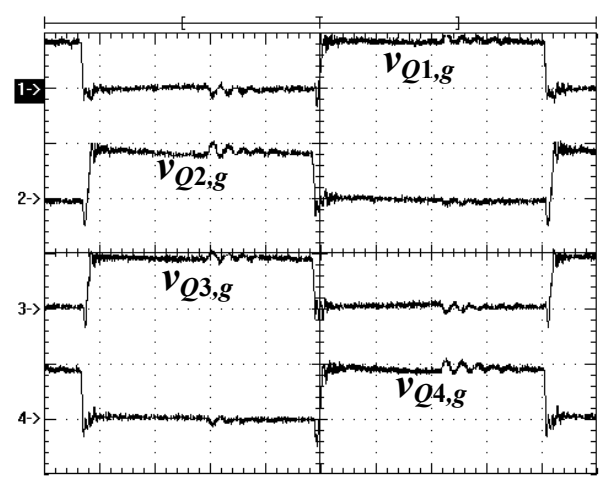

(a)

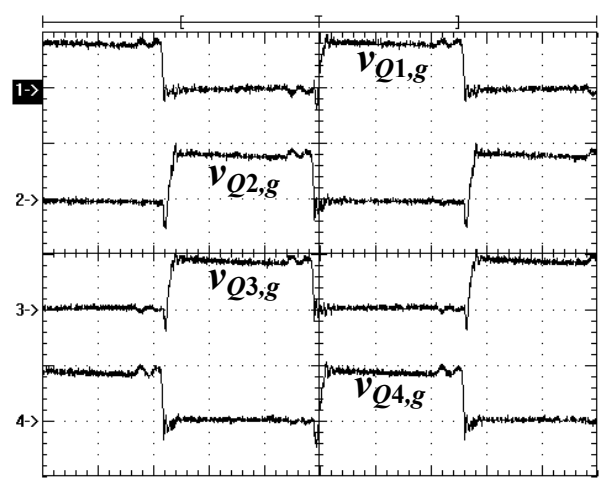

(b)

Figure 11. Measured PWM signals of $Q_{1} \sim Q_{4}$ for reverse power operation and full load (a) $V_{L}=36 \mathrm{~V}$ (b) $V_{L}=52 \mathrm{~V}\left(v_{Q 1, g_{s} \sim v_{Q 4, g s}}: 10 \mathrm{~V} /\right.$ div; time: $\left.2 \mu \mathrm{s}\right)$.

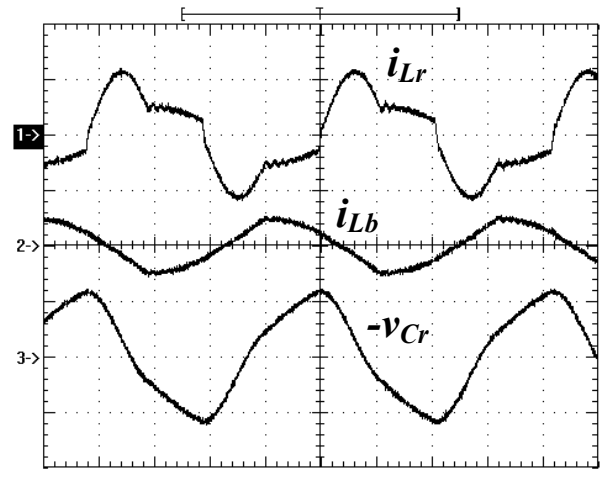

(a)

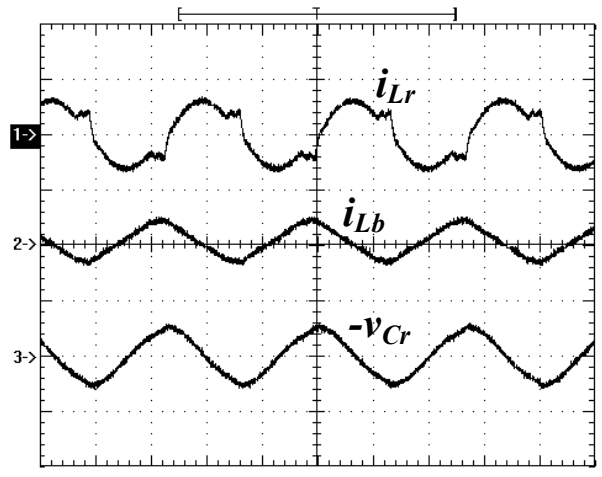

(b)

Figure 12. Measured results of $i_{L r}, i_{L b}$ and $v_{C r}$ for reverse power operation and full load (a) $V_{L}=36 \mathrm{~V}$ (b) $V_{L}=52 \mathrm{~V}\left(i_{L r}, i_{L b}: 10 \mathrm{~A} / \mathrm{div} ; v_{C r}: 500 \mathrm{~V} /\right.$ div; time: $\left.4 \mu \mathrm{s}\right)$.

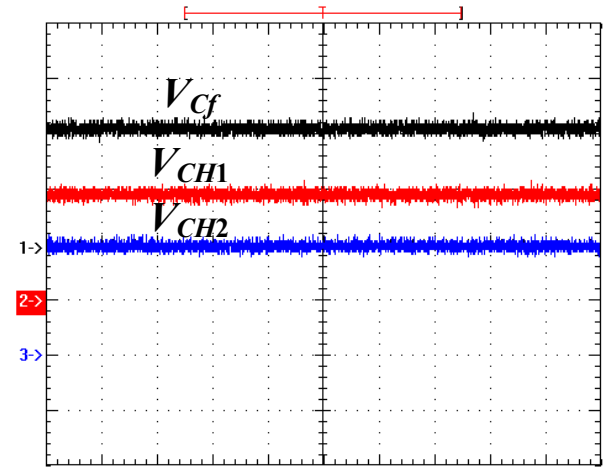

Figure 13. Measured results of $V_{C f}, V_{C H 1}$, and $V_{C H 2}$ under reverse power operation and full load $\left(v_{C f}, V_{C H 1}, V_{C H 2}, V_{D a}, V_{D b}: 200 \mathrm{~V} /\right.$ div; time: $\left.4 \mu \mathrm{s}\right)$. 


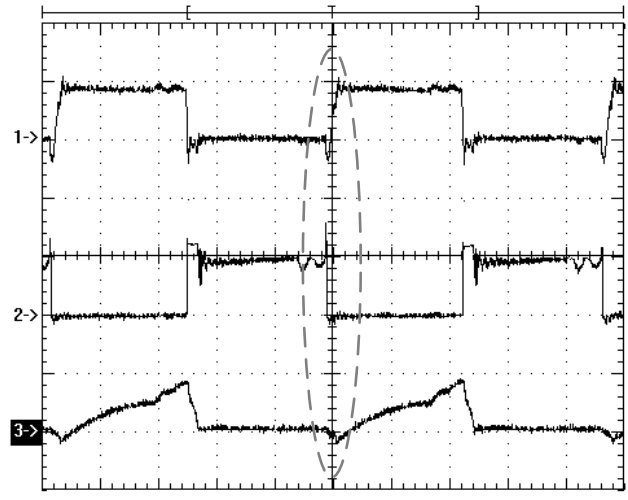

(a)

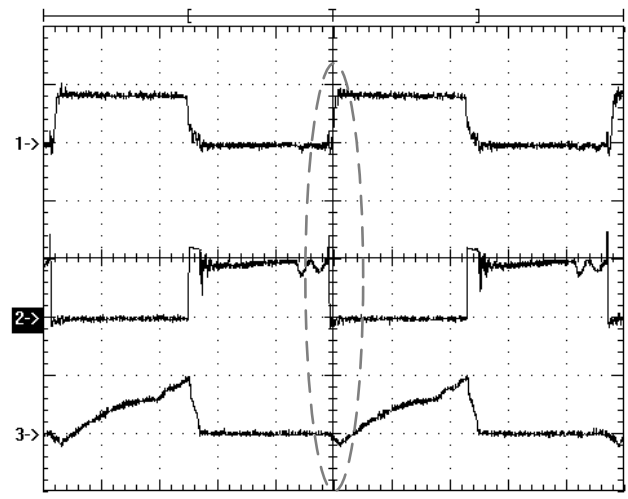

(c)

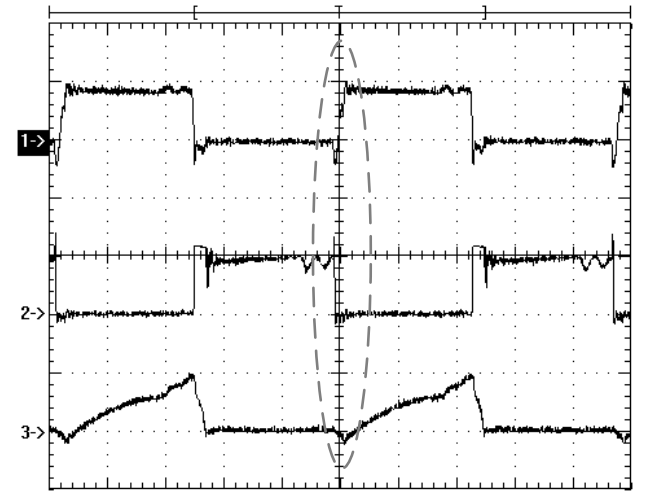

(b)

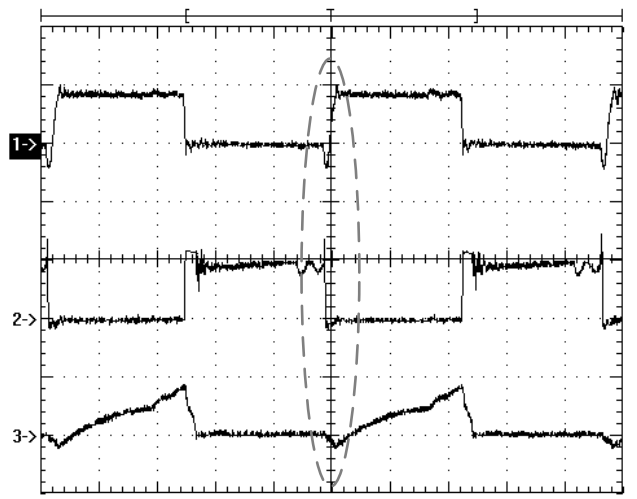

(d)

Figure 14. Measured waveforms of power devices $Q_{1} \sim Q_{4}$ under reverse power operation and $20 \%$ load (a) $Q_{1}$ waveform (b) $Q_{2}$ waveform (c) $Q_{3}$ waveform (d) $Q_{4}$ waveform ${ }^{(} v_{Q 1, g}-v_{Q 4, g}: 10 \mathrm{~V} /$ div; $v_{Q 1, d} v_{Q 4, d}: 50 \mathrm{~V} /$ div; $i_{Q 1}-i_{Q 4}: 20 \mathrm{~A} /$ div; time: $\left.2 \mu \mathrm{s}\right)$

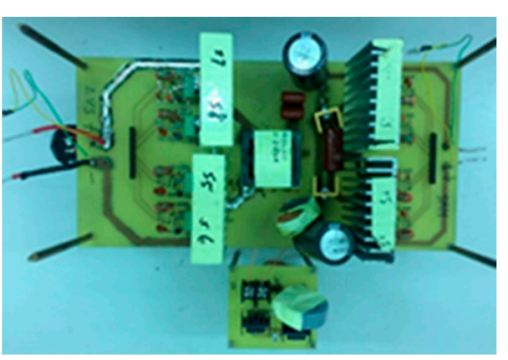

(a)

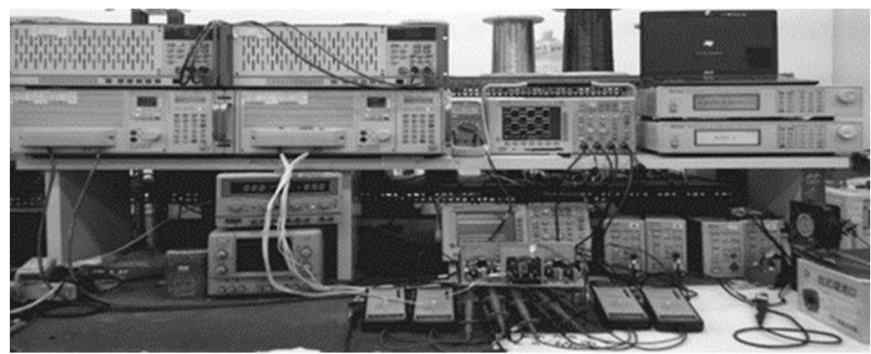

(b)

Figure 15. Pictures of the presented circuit: (a) prototype circuit; (b) experimental setup.

\section{Conclusions}

A new three-level resonant converter is proposed, analyzed, and discussed to realize bidirectional power transfer and soft switching operation capability. A three-level diode clamp series resonant converter is used on the high-voltage side to have low voltage rating on active devices. For forward power operation, the conventional LLC circuit is selected to have ZVS operation on all power switches. Full-wave rectifier with synchronous switches is adopted on the low-voltage side to reduce conduction loss on power semiconductors. To overcome the low voltage gain problem on conventional $L L C$ converter under reverse power operation, a parallel inductor is connected to the leg terminal of three-level diode-clamp resonant converter. Thus, the proposed converter can achieve voltage step-up and step-down for forward and reverse power operation by using PFM scheme. Compared to the 
bidirectional LLC circuit [15], the proposed converter can achieve ZVS operation for both power flow directions. Compared to the symmetric LLC converters in [16-18], the proposed LLC converter has less freewheeling current on primary-side for forward power operation. However, one ac switch is needed in the studied circuit compared to conventional bidirectional LLC circuit topology. Finally, the theoretical analysis is confirmed by experiments with a laboratory prototype.

Author Contributions: B.-R.L. designed this project and was responsible for formal analysis, writing and editing this paper. W.-P.L. measured the experimental waveforms. All authors have read and agreed to the published version of the manuscript.

Funding: This work was supported by the Ministry of Science and Technology, Taiwan, under research project MOST 108-2221-E-224-022-MY2.

Conflicts of Interest: The authors declare no conflict of interest.

\section{References}

1. Lin, B.-R.; Zhuang, Y.-S. Hybrid resonant converter with three half-bridge legs for wide voltage operation. Appl. Sci. 2020, 10, 310. [CrossRef]

2. Lin, B.-R.; Lin, G.-H. DC converter with wide soft switching operation, wide input voltage and low current ripple. Appl. Sci. 2020, 10, 4672. [CrossRef]

3. Jing, W.; Lai, C.H.; Wong, S.H.W.; Wong, M.L.D. Battery-super capacitor hybrid energy storage system in standalone dc microgrids: A review. IET Renew. Power Gener. 2017, 11, 461-469. [CrossRef]

4. Guerrero, J.M.; Loh, P.C.; Lee, T.-L.; Chandorkar, M. Advanced Control Architectures for Intelligent Microgrids-Part II: Power Quality, Energy Storage, and AC/DC Microgrids. IEEE Trans. Ind. Electron. 2013, 60, 1263-1270. [CrossRef]

5. Lin, B.-R.; Dai, C.-X. Wide voltage resonant converter using a variable winding turns ratio. Electronics 2020, 9, 370. [CrossRef]

6. Meng, L.; Shafiee, Q.; Trecate, G.F.; Karimi, H.; Fulwani, D.; Lu, X.; Guerrero, J.M. Review on control of DC microgrids and multiple microgrid clusters. IEEE J. Emerg. Sel. Top. Power Electron. 2017, 5, 928-948.

7. Emadi, A.; Lee, Y.J.; Rajashekara, K. Power electronics and motor drives in electric, hybrid electric, and plug-in hybrid electric vehicles. IEEE Trans. Ind. Electron. 2008, 55, 2237-2245. [CrossRef]

8. Zhang, Y.; Gao, Y.; Li, J.; Sumner, M. Interleaved switched-capacitor bidirectional dc-dc converter with wide voltage-gain range for energy storage systems. IEEE Trans. Power Electron. 2018, 33, 3852-3869. [CrossRef]

9. Shen, C.-L.; Shen, Y.-S.; Chiu, P.-C.; Liang, T.-C. Isolated bidirectional converter with minimum active switches for high-voltage ratio achievement and micro-grid applications. IET Power Electron. 2017, 10, 2208-2216. [CrossRef]

10. Mangu, B.; Akshatha, S.; Suryanarayana, D.; Fernandes, B.G. Grid-connected PV-wind-battery-based multi-input transformer-coupled bidirectional dc-dc converter for household applications. IEEE J. Emerg. Sel. Top. Power Electron. 2016, 4, 1086-1095. [CrossRef]

11. Yilmaz, M.; Krein, P.T. Review of battery charger topologies, charging power levels, and infrastructure for plug-in electric and hybrid vehicles. IEEE Trans. Power Electron. 2013, 28, 2151-2169. [CrossRef]

12. Ahrabi, R.R.; Ardi, H.; Elmi, M.; Ajami, A. A novel step-up multiinput DC-DC converter for hybrid electric vehicles application. IEEE Trans. Power Electron. 2017, 32, 3549-3561. [CrossRef]

13. Xu, D.; Zhao, C.; Fan, H. A PWM plus phase-shift control bidirectional DC-DC converter. IEEE Trans Power Electron. 2004, 19, 666-675. [CrossRef]

14. Tao, H.; Kotsopoulos, A.; Duarte, J.L.; Hendrix, M.A.M. Family of multiport bidirectional DC-DC converters. IEE Proc. Electr. Power Appl. 2006, 153, 451-458. [CrossRef]

15. Pledl, G.; Tauer, M.; Buecherl, D. Theory of operation, design procedure and simulation of a bidirectional LLC resonant converter for vehicular applications. In Proceedings of the IEEE Vehicle Power and Propulsion Conference (VPPC 2010), Lille, France, 1-3 September 2010; pp. 1-5.

16. Tan, K.; Yu, R.; Guo, S.; Huang, A.Q. Optimal design methodology of bidirectional LLC resonant DC/DC converter for solid state transformer application. In Proceedings of the IECON 2014-40th Annual Conference of the IEEE Industrial Electronic Society, Dallas, TX, USA, 29 October-1 November 2010; pp. 1657-1664. 
17. Jiang, T.; Zhang, J.; Wu, X.; Sheng, K.; Wang, Y. A bidirectional LLC resonant Converter with automatic forward and backward mode transition. IEEE Trans. Power Electron. 2015, 30, 757-770. [CrossRef]

18. Kim, E.-S.; Park, J.-H.; Jeon, Y.-S.; Kong, Y.-S.; Lee, S.-M.; Kim, K. Bidirectional secondary LLC resonant converter using auxiliary switches and inductor. In Proceedings of the 2014 IEEE Applied Power Electronics Conference and Exposition-APEC 2014, Fort Worth, TX, USA, 16-20 March 2014; pp. 1941-1947.

Publisher's Note: MDPI stays neutral with regard to jurisdictional claims in published maps and institutional affiliations.

(C) 2020 by the authors. Licensee MDPI, Basel, Switzerland. This article is an open access article distributed under the terms and conditions of the Creative Commons Attribution (CC BY) license (http://creativecommons.org/licenses/by/4.0/). 